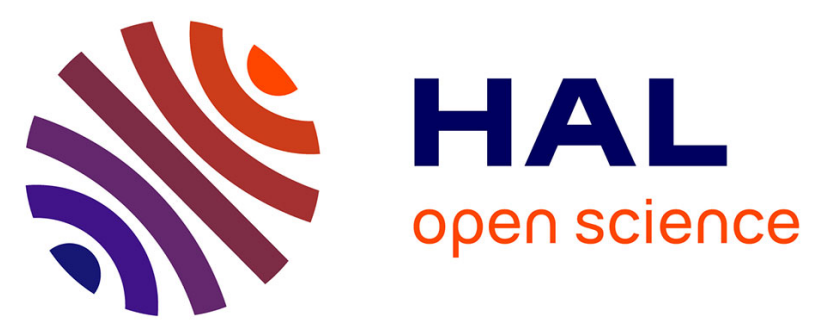

\title{
Simulation of orthotic treatment in adolescent idiopathic scoliosis using a subject-specific finite element model
}

Claudio Vergari, Isabelle Courtois, Eric Ebermeyer, Houssam Bouloussa, Raphaël Vialle, Wafa Skalli

\section{- To cite this version:}

Claudio Vergari, Isabelle Courtois, Eric Ebermeyer, Houssam Bouloussa, Raphaël Vialle, et al.. Simulation of orthotic treatment in adolescent idiopathic scoliosis using a subject-specific finite element model. Société de Biomécanique (40éme Congrès), Oct 2015, Paris, France. pp.2076-2077, 10.1080/10255842.2015.1069629 . hal-03237092

\section{HAL Id: hal-03237092 \\ https://hal.science/hal-03237092}

Submitted on 26 May 2021

HAL is a multi-disciplinary open access archive for the deposit and dissemination of scientific research documents, whether they are published or not. The documents may come from teaching and research institutions in France or abroad, or from public or private research centers.
L'archive ouverte pluridisciplinaire $\mathbf{H A L}$, est destinée au dépôt et à la diffusion de documents scientifiques de niveau recherche, publiés ou non, émanant des établissements d'enseignement et de recherche français ou étrangers, des laboratoires publics ou privés. 


\title{
Simulation of orthotic treatment in adolescent idiopathic scoliosis using a subject-specific finite element model
}

\author{
C. Vergari ${ }^{\mathrm{a}, *}$, I. Courtois ${ }^{\mathrm{b}}$, E. Ebermeyer ${ }^{\mathrm{b}}$, H. Bouloussa ${ }^{\mathrm{c}}$, R. Vialle ${ }^{\mathrm{c}}$ and W. Skallia \\ ${ }^{a}$ Arts et Metiers ParisTech, LBM/Institut de Biomecanique Humaine Georges Charpak, 151 bd de l'Hopital 75013 PARIS \\ - FRANCE; ${ }^{b}$ Unite Rachis, CHU - Hopital Bellevue, 25 boulevard Pasteur 42100 Saint-Etienne, France; ${ }^{c}$ Department of \\ Paediatric Orthopaedics, Armand Trousseau Hospital, Université Pierre et Marie Curie-Paris 6, 75571, Paris, France
}

Keywords: trunk; finite element; model validation.

\section{Introduction}

Adolescent idiopathic scoliosis (AIS) is a threedimensional deformity of the spine, often progressing rapidly during the growth spurt. Severe scoliosis can lead to significant degradation of quality of life and functional impairment; the aim of early orthotic treatment is to slow down curvature progression until skeletal maturity. Efficacy of bracing has often been questioned (Negrini et al., 2010; Weinstein et al., 2013), and often relies on the orthotist's experience since objective methods to design and predict brace action are still in development (Cobetto et al., 2014). A clinically-relevant method for the evaluation of brace simulation in AIS was recently presented (Vergari et al., 2015) and applied to preliminarily validate a finite element model (FEM) of the trunk. The aim of this work was to improve the simulation of brace action on scoliotic trunks and to validate the model on a larger cohort.

\section{Methods}

\subsection{Subjects}

Forty-two subjects were included both retrospectively and prospectively in this study (38 girls and 4 boys between 7 and 17 years old, $26.2^{\circ} \pm 14.4^{\circ} \mathrm{Cobb}$ angle). All were diagnosed with AIS and prescribed an orthotic treatment. Stereoradiographs were acquired both at the moment of treatment decision and in-brace, between 0 (i.e. same day) and 7 months later. The study was approved by the ethical committee (CPP 6001 Ile de France V).

\subsection{Finite element model}

A previously described subject-specific FEM was automatically built (Vergari et al., 2015) from pelvic, spinal and ribcage 3D reconstructions (Aubert et al., In Press; Humbert et al., 2009).
The pelvis and $\mathrm{T} 1$ vertebra were displaced from the out of brace to the in-brace configuration, in order to maintain proper subject balance. Brace pad placement was retrieved from soft tissue deformation and radiopacity in radiographic images. Those pads acting on the ribcage were implemented in the simulation as cylindrical structures (485 nodes, 433 hexahedral elements, 0.01 MPa Young's modulus). Pads acting directly on the spine (e.g. in the lumbar region or on the back) were implemented by applying displacements to the corresponding vertebrae. Displacements were calculated from the $3 \mathrm{D}$ reconstruction of the subject with and without bracing.

\subsection{Evaluation}

Simulations were evaluated by calculating the root mean square error (RMSE) between the clinical indices as measured on the in-brace $3 \mathrm{D}$ reconstruction and those extracted from the simulation. Error tolerances (Table 1) were estimated by combining the measurement uncertainty involved in comparing two 3D reconstructions. Vertebral positions and orientations were also evaluated.

\section{Results and discussion}

Average computation time was about 15 minutes. Global RMSEs are reported in Table 1, while Figure 1 reports an example of brace action and simulation of spinal midline.

Errors were smaller than the defined tolerances in the lateral (kyphosis and lordosis), frontal (Cobb angle) and axial planes (axial rotation). All subjects presented an error in T1-T12 kyphosis smaller than the tolerance; $80 \%$ of the subjects were in the tolerance range for the Cobb angle and apical axial rotation. $86 \%$ of the subjects presented smaller errors than tolerance for torsion $\left(5^{\circ}\right)$ and $90 \%$ for $3 \mathrm{D}$ rib hump $\left(7^{\circ}\right)$.

\subsection{Border conditions}

*Corresponding author. Email: c.vergari@gmail.com 


\begin{tabular}{|c|c|c|c|}
\hline & $\begin{array}{c}\text { T1/T12 } \\
\text { Kyphosis }\end{array}$ & $\begin{array}{c}\text { Cobb } \\
\text { angle }\end{array}$ & $\begin{array}{c}\text { Apical axial } \\
\text { rotation }\end{array}$ \\
\hline Tolerance & $8^{\circ}$ & $5^{\circ}$ & $5^{\circ}$ \\
\hline RMSE & $2.5^{\circ}$ & $4.1^{\circ}$ & $3.9^{\circ}$ \\
\hline Max error & $6.7^{\circ}$ & $8.7^{\circ}$ & $9.3^{\circ}$ \\
\hline
\end{tabular}

Table 1. Global simulation errors and error tolerances

Global RMSE in vertebral position was $1.9 \mathrm{~mm}$, with an error of $2.3 \mathrm{~mm}$ in lateral direction, $2.1 \mathrm{~mm}$ in antero-posterior and $0.9 \mathrm{~mm}$ in vertical direction.

In the previously presented work (Vergari et al., 2015), pad action on the ribcage was modelled by displacing those nodes corresponding to the pad region. Global errors were smaller in the present study, with a decrease of T1-T12 kyphosis RMSE of $1.2^{\circ}$, for instance, $1.6^{\circ}$ of Cobb angle and $3.1^{\circ}$ in apical axial rotation.

Because of the measurement uncertainty of the $3 \mathrm{D}$ reconstruction used to build the out of brace and inbrace geometries, rib length is not exactly the same in the two cases. The previous method of pad implementation therefore induced local deformations and high local stresses due to lengthening, shortening or sharp bending of rib elements.

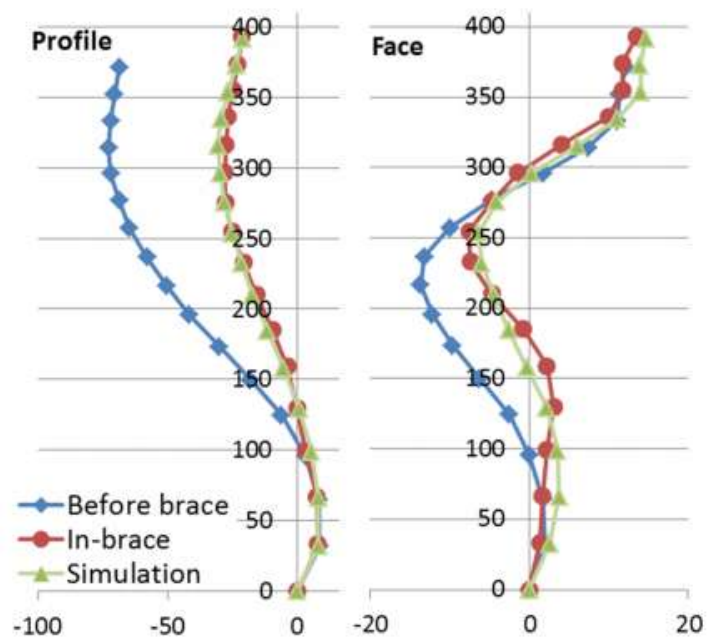

Figure 1 Spinal midline and vertebral locations (units are in $\mathrm{mm}$ )

Pads were explicitly represented and were implemented as solid objects acting by mechanical contact on the rib cage. This eliminates the local deformation that affected the previous version, yielding more natural in-brace geometry. The forces resulting on the pad can now be analysed to investigate brace comfort, and potentially be integrated in brace design.

\section{Conclusions}

This work provides a robust validation in 42 scoliotic patients of an existing finite element model for the simulation of brace action on the scoliotic spine. While validation should be pursued on a larger cohort, this model could potentially be applied in brace design and improvement.

\section{Acknowledgements}

The authors are grateful to the ParisTech BiomecAM chair program on subject-specific musculoskeletal modelling (with the support of ParisTech and Yves Cotrel Foundations, Société Générale, Proteor and Covea) and to the "Investissements d'Avenir" program for funding. We would also like to thank Mrs Pauline Lallemant and Ms Sonia Simoes for their technical help.

\section{References}

Aubert B, Vergari C, Ilharreborde B, Courvoisier A, Skalli W. In Press. 3D Reconstruction of rib cage geometry from biplanar radiographs using a statistical parametric model approach. Comput Methods Biomech Biomed Eng Imaging Vis.

Cobetto N, Aubin CE, Clin J, Le May S, DesbiensBlais F, Labelle H, Parent S. 2014. Braces Optimized With Computer-Assisted Design and Simulations Are Lighter, More Comfortable, and More Efficient Than Plaster-Cast Braces for the Treatment of Adolescent Idiopathic Scoliosis. Spine Deformity. 2:276-284.

Humbert L, De Guise JA, Aubert B, Godbout B, Skalli W. 2009. 3D reconstruction of the spine from biplanar X-rays using parametric models based on transversal and longitudinal inferences. Med Eng Phys 31, 681-687.

Negrini S, Minozzi S, Bettany-Saltikov, Zaina F, Chockalingam N, Grivas TB, Kotwicki T, Maruyama T, Romano M, Vasiliadis ES. 2010. Braces for idiopathic scoliosis in adolescents. Cochrane Database Syst Rev. CD006850.

Vergari C, Ribes G, Aubert B, Adam C, Miladi L, Ilharreborde B, Abelin-Genevois K, Rouch P, Skalli W. 2015. Evaluation of a patient-specific finite element model to simulate conservative treatment in adolescent idiopathic scoliosis. Spine Deformity 3, 4-11.

Weinstein SL, Dolan LA, Wright JG, Dobbs MB. 2013. Effects of bracing in adolescents with idiopathic scoliosis. N Engl J Med. 369:1512:1521. 